\title{
Improving human health through optimizing food intake and exercise time management: a real-world science
}

\begin{abstract}
Synopsis
Eating-Exercise timing management as a real-world science requires profound contemplations in modern medical and nutritional sciences as well as public health and education programs. Endocrinologically, human peripheral cells may not effectively tolerate glucose and other energizers during evening and night times. This is basically because nutrients are needed mostly during active times of the circadian period or morning and day times. This forum article formulates and empowers a practical postmodern strategy to reduce evening food intake but to increase evening exercise to more effectively and more healthfully manage intermediary metabolism and endocrinology. These should reflect in reduced risks from abdominal adiposity, metabolic syndrome, diabetes mellitus, hypertension, obesity and cardiovascular abnormalities. Evening exercise is persuaded to help accomplish eating regimen related goals
\end{abstract}

Special Issue - 2015

\author{
Akbar Nikkhah \\ Department of Animal Sciences, University of Zanjan, Iran
}

\begin{abstract}
Correspondence: Akbar Nikkhah, Chief Highly Distinguished Professor, Department of Animal Sciences, Faculty of Agricultural Sciences, University of Zanjan, Foremost Principal Highly Distinguished Elite-Generating Scientist, National Elite Foundation, Iran, Email anikkha@yahoo.com
\end{abstract}

Received: October I, 2015 | Published: October 5, 2015

Keywords: metabolism, health, eating timing, exercise, lifestyle

\section{Philosophy and critical discussion}

A deeper understanding of human physiology depends on optimal understanding of comparative interspecies physiology. Animal physiology can be more effectively perceived via incomparable insights into greatly integrative ruminant physiology and rumen microbial physiology. ${ }^{1-3}$ Ruminants are matchless food resources that should be benefited from as appropriate working pattern models for studying human medicine and health at various gene, cell, organ and individual entire body levels. ${ }^{4,5}$ For example, night-time vs. daytime feeding of dairy cows has increased eating rate and postprandial release of intermediary metabolites from both rumen and post-rumen as well as splanchnic and peripheral tissues. ${ }^{6,7}$ Nocturnal eating has also increased milk production of especially fat and energy. ${ }^{8}$ Night eating, in addition, improved nutrient digestibility and efficiency in dairy and beef cattle. ${ }^{5}$ The discoveries of such kind underline the feasibility and importance of timing of eating and exercise as a strategy to better orchestrate nutrient metabolism and partitioning in human. ${ }^{9-11}$ However, it must be noted that livestock are different from human in the extent and rate of splanchnic, hepatic and mammary metabolism. It is expected that modulating eating time would have likely different impacts on ruminant vs. human nutriphyiogenomics and endocrinology. This requires future concentration on interdisciplinary and interspecies nutritional and metabolism experiments.

Basically, human levels of circulating blood glucose normally elevate at the end of the passive nocturnal phase that is the commencement of the active phase or day-time. The early morning glucose rise, from a behaviour perspective, occurs perhaps at the expectancy of the upcoming activity phase. ${ }^{10}$ The peripheral increases in glucose concentrations may be synchronous with increases in levels of corticosterone, thus increasing glucose delivery to a variety of cells that ultimately raise demands for insulin. ${ }^{11}$ The morning rises in glucose levels are at least in part induced by somatotropin related induction of hepatic glucose neogenesis. Melatonin release is stimulated by darkness and can additionally increases postprandial insulin requirements. ${ }^{12}$ This is partly due to less responsive insulin to glucose surges during evening and night times. Night-time glucose intolerance may be partially owing to elevated melatonin secretion. This is also a reflection of drops in glucose needs over the course of night or inactivity/less activity period.

Glucose tolerance has an evolutionary root that reflects how working and resting human body manages substrate supply and demand over light and dark circadian phases. Making nigh-time food meals smaller has the advantage of allowing intermediary hormones such as melatonin, insulin, somatotropin, and corticosterones to more effectively inter-play metabolic roles in coping with the human circadian nature. As such, shift-workers and nocturnal food consumers would encounter rather mismanaged circadian patterns of metabolism. Thus, it is crucially important to well synchronize internal and external synchronizers of human metabolism and physiology through minimizing nocturnal eating and increasing evening physical exercise. ${ }^{13,14}$ This is to improve glucose tolerance and insulin sensitivity and reduce obesity and diabetes risks. ${ }^{15-20}$ Research is much needed to explore further aspects of this circadian human health philosophy. ${ }^{20-23}$

\section{Implications}

Gaining insights from recent livestock metabolic models, an innovative real-world metabolic strategy was critically formulated to effectively time-manage eating and exercise for improved endocrinology and metabolism. Reduced evening eating matched with increased late afternoon and evening physical work should allow human cells to welcome glucose and healthfully manage nocturnal glucose assimilation. Among the major outcomes is reduced risk from obesity and diabetes. 


\section{Acknowledgments}

Thanks to the Ministry of Science Research and Technology and National Elite Foundation for supporting the author's global programs of optimizing science edification.

\section{Conflict of interest}

Author declares that there is no conflict of interest.

\section{References}

1. Nikkhah A. Eating time modulations of physiology and health: life lessons from human and ruminant models. Iranian J Basic Med Sci. 2012;15(4):891-899.

2. La Fleur SE, Kalsbeek A, Wortel J, et al. A daily rhythm in glucose tolerance: a role for the suprachiasmatic nucleus. Diabetes. 2001;50(6):1237-1243.

3. Sehgal A. Molecular Biology of Circadian Rhythms. NJ, Hoboken: John Wiley \& Sons, Inc; 2004.

4. Nikkhah A. Chronophysiology of ruminant feeding behavior and metabolism: an evolutionary review. Biol Rhythm Res. 2013;44(2):197-218.

5. Nikkhah A. Ruminant chronophysiological management: an emerging bioscience. Open Access Anim Physiol. 2011;3:9-12.

6. Nikkhah A. Bioscience of ruminant intake evolution: feeding time models. Adv Biosci Biotechnol. 2011;2:271-274.

7. Nikkhah A. Timing of feeding: a postmodern management strategy to modulate chronophysiological rhythms in rumen fermentation kinetics. Biol Rhythm Res. 2014;45(4):533-540.

8. Nikkhah A. Time of Feeding an Evolutionary Science. Germany: Lap Lambert Publishing, GmbH \& Co. KG; 2012.

9. Arslanian S, Ohki Y, Becker DJ, et al. Demonstration of a dawn phenomenon in normal adolescents. Horm Res. 1990;34(1):27-32.

10. Nikkhah A, Furedi CJ, Kennedy AD, et al. Effects of feed delivery time on feed intake, rumen fermentation, blood metabolites and productivity of lactating cows. J Dairy Sci. 2008;91:1-12.
11. La Fleur SE. Daily rhythms in glucose metabolism: suprachiasmatic nucleus output to peripheral tissue. JNeuroendocrinol. 2003;15:315-322.

12. La Fleur SE, Kalsbeek A, Wortel J, et al. Role for the pineal and melatonin in glucose homeostasis: pinealectomy increases night-time glucose concentrations. J Neuroendocrinol. 2001;13(12):1025-1032.

13. Nikkhah A. Eating Timing and Diabetes. Int J Diabetol Vas Dis Res. 2014;2(2):1.

14. Nikkhah A. Science of eating time: A novel chronophysiological approach to optimize glucose-insulin dynamics and health. J Diabetes Mellitus. 2011;2(1):8-11.

15. Nikkhah A. Diabesity and Lifestyle. Curr Res Diabetes Obes J. 2015;1(1):CRDOJ.MS.ID.555552.

16. Nikkhah A. Lifestyle Optimization: Today's Foremost Probiotic. J Probiotics Health. 2015;3:e119.

17. Nikkhah A. Improving Life Quality via Circadian Timing of Nutrient Intake: Linking Ruminant Agriculture to Human Health. EC Agriculture. 2015;2(1):258-259.

18. Nikkhah A. Optimized Lifestyle via Timing of Food Intake: Bridging Ruminant Agriculture to Human Health. J J Food Nutri 2(2): 013.

19. Nikkhah A. Scheduling Exercise-Eating to Optimize Gut Probiotics: A Global Invention. J Probiotic Health. 2015;3:e118.

20. Nikkhah A. Timing of Intake and Exercise: Creating a Robust Public Science. J Nutr Food Sci In Press. 2015.

21. Nikkhah A. Evening Exercise to Prevent Central Adiposity and Cardiometabolic Diseases. International Journals of Diabetology \& Vascular Disease Research. 2015;3(6):113-114.

22. Nikkhah A. Running as a Postmodern Probiotic to Optimize Gut Physiology and Health. J Prob Health. 2015;3:1.

23. Nikkhah A. Arts, the Core of Sustainable Food and Agriculture: Brain Fruition. Adv Crop Sci Technol. 2015;3:e124. 